\title{
Pirazin Sübstitüe Kaliks[4]arenin Bazı Toksik Metal ve Oksianyon Ekstraksiyon Özelliklerinin İncelenmesi
}

\author{
Ömer GÜNGÖR* \\ Kocaeli Üniversitesi, Hereke Ömer İsmet Uzunyol MYO, Kimya ve Kimyasal İşleme Teknikleri Bölümü, Kocaeli \\ (ORCID: 0000- 0002-3835-2920)
}

\begin{abstract}
$\ddot{O} z$
Bu çalışmada, kaliks[4]arenin pirazin-2-karboksilat türevi (3) sentezlenmiş ve yapısı spektroskopik yöntemler ile karakterize edilmiştir. Ayrıca, bu bileşik büyük çevresel problemlere sebep olan toksik özelliğe sahip metaller $\left(\mathrm{Na}^{+}, \mathrm{K}^{+}, \mathrm{Co}^{2+}, \mathrm{Ni}^{2+}, \mathrm{Cu}^{2+}, \mathrm{Cd}^{2+}, \mathrm{Pb}^{2+}\right.$ ve $\mathrm{Hg}^{2+}$ ) ve oksianyonların'ın (kromat ve arsenat) sivi-sivı ekstraksiyon çalışmalarında kullanılmıştır. Ekstraksiyon sonuçlarına göre düşük $\mathrm{pH}$ larda kromat $(\mathrm{pH}=1,5)$ ve arsenat $(\mathrm{pH}=3,5)$ anyonlarının yüksek oranda sulu fazdan organik faza taşındığı̆ görülmüşsür. Kaliksaren türevi (3) ile oksianyonlar arasındaki kompleks oranı Job's Plot analiz yöntemi ile 1:1 olarak tespit edilmiştir. Ayrıca Bileşik 3, çalışılan toksik metalleri ise yüksek oranda sulu fazdan organik faza taşımıştır.
\end{abstract}

Anahtar kelimeler: Kaliksaren, Kromat, Arsenat, Sıv1-sıvı Ekstraksiyon, Toksik Metal

\section{Investigation of Some Toxic Metal and Oxyanion Extraction Properties of Pirazine Substituted Calix[4]arene}

\begin{abstract}
In this study, pyrazine-2-carboxylate derivative of calix[4]arene was synthesized and the structure was characterized by spectroscopic methods. In addition, this compound was used as carrier in the liquid-liquid extraction studies for toxic metals and oxyanions (chromate and arsenate) which cause major environmental problems. According to the extraction results, it was observed that the chromate $(\mathrm{pH}=1.5)$ and arsenate $(\mathrm{pH}=$ 3.5) anions were removed from the waste water at low $\mathrm{pH}$ levels. The stoichiometric complex ratio between calixarene derivative (3) and oxyanions was estimated through Job's Plot and it was found to be 1: 1. Also, compound $\mathbf{3}$ carried the studied toxic metals from the aqueous phase to the organic phase.
\end{abstract}

Keywords: Calixarene, Chromate, Arsenate, Liquid-liquid Extraction, Toxic Metal

\section{Giriş}

Kaliksarenler, p-sübstitüe fenol ve formaldehit kondenzasyonu ile C. David Gutsche tarafindan 1974 yılında elde edilen kupa şeklindeki moleküllerdir. Sentezlerinin kolay olması ve çok yönlü fonksiyonlandırılabilmelerinin yanısıra 3D iskelete sahip olan kaliksarenler, siklodekstrin ve taç eterlerden sonra subramoleküler kimyanın üçüncü jenerasyonu olarak bilinmektedir. Ayrıca üst ve alt kısımlarından (upper and lower rim) farklı olarak sübstitüe edilebilmeleri kaliksarenlere ayrı bir önem kazandırmaktadır [1]. Bu bileşiklerin; molekül ve iyon taşıyıcı, iyon selektif elektrot, HPLC'de sabit faz, monolayer, sıvı membran çalışmalarında taşıyıcı, enzim mimik katalizörü gibi birçok kullanım alanı vardır. Kaliksarenler, aril halkasının yukarı ve aşağı yönlenmelerine göre çözelti içerisinde farklı konformasyonlara sahip olabilmektedirler. Kaliks[4]arenler, 1,2 karş1lıkl1, 1,3 karşılıklı, kısmi koni ve koni olmak üzere 4 konformasyona sahiptirler [2]. Kaliksarenler 4 ila 20 arasında farklı aril halkasına sahip olduklarından farklı molekül boşluğuna (cavite) sahiptirler. Ayrıca bu halka boşluğuna uygun olan çeşitli molekül ve iyonlar ile kompleks oluşturabilmektedirler [3].

*Sorumlu yazar: omer.gungor@kocaeli.edu.tr

Geliş Tarihi:20.02.2019, Kabul Tarihi: 01.07.2019 
Endüstriyel gelişmeler ve her geçen gün sanayide kullanılan kimyasal sayısı ve oranının artması maalesef çevre kirliliğinin de artmasına sebep olmaktadır. Metaller endüstride en çok kullanılan kimyasallardandır. $\mathrm{Bu}$ metallerin doğaya bırakılması canlılar üzerinde ciddi sağlı problemlerine yol açtıkları bilinmektedir. Kurşun özellikle kemik dokularına zarar verirken cıva ve kadmiyum böbrek rahatsızlıklarına sebep olmaktadır [4].

Kromat, elektro kaplama, kağıt üretimi, tabaklama, bronz, cevher ve petrol rafineri gibi birçok endüstriyel proses tarafindan kullanılmaktadır. Hindistan'daki tabakhanelerin yaklaşık \% 80'i krom tabaklama işlemi yapmaktadır ve bu işletmelerin büyük bir çoğunluğu atık sularını çevreye boşaltmaktadırlar [5]. Kromatlar [Cr(VI)] güçlü oksitleyici olduklarından bitki, hayvanlar ve insanlar için toksiktirler. İçme suyundaki çözünmüş $\mathrm{Cr}$ için mevcut sınır, bazı endüstriyel atık solüsyonlarının çevreye deşarj edilmeden önce $\mathrm{Cr}(\mathrm{VI})$ konsantrasyonlarının azaltılması gereken seviye olan $10^{-6} \mathrm{M}^{\prime} \mathrm{dir}$. Sulu atıklarda $\mathrm{Cr}(\mathrm{VI})$, asidik ortamlarda dikromat $\left(\mathrm{Cr}_{2} \mathrm{O}_{7}{ }^{2-)}\right.$ veya alkali ortamlarda kromat $\left(\mathrm{CrO}_{4}^{-}\right)$olarak bulunur [6].

Arsenik, toksik ve kanserojen bir bileşiktir [7]. Doğada, inorganik arsenik türleri olarak arsenat (yükseltgenme basamağ $1+5$ ) ve arsenit (yükseltgenme basamağ $1+3$ ) yaygın olarak bulunmaktadır. Sulu ortamda arsenit türleri $\left(\mathrm{H}_{3} \mathrm{AsO}_{3}, \mathrm{H}_{2} \mathrm{AsO}_{3}{ }^{-}, \mathrm{HAsO}_{3}{ }^{2-}\right.$ ve $\left.\mathrm{AsO}_{3}{ }^{3-}\right)$ ve arsenat türleri $\left(\mathrm{H}_{3} \mathrm{AsO}_{4}, \mathrm{H}_{2} \mathrm{AsO}_{4}{ }^{-}\right.$, $\mathrm{HAsO}_{4}{ }^{2-}$ ve $\mathrm{AsO}_{4}{ }^{3-}$ ) baskındır. Arsenik içme sularında bulunduğunda deri kalınlaşması, pigmentasyon değişikliği, adale zayıflığı, nörolojik bozukluğuna ayrıca mesane, deri, akciğer ve böbrek kanserine sebep olmaktadır [8-11]. İnorganik arsenik zehirlenmesine oral yoldan maruz kalınması halinde akut toksisite semptomları bulantı, kas krampları, kusma, epigastrik ve karın ağrısı, dermatit, anoreksi, kalp anormallikleri ve hepatotoksisitedir [12-14]. Dünya Sağlık Örgütünün(WHO) içme suyunda tavsiye ettiği arsenik sınır değeri $10 \mu \mathrm{g} / \mathrm{lt}$ 'dir [15]. Yer altı sularında arsenik problemi olan başlıca ülkeler arasında Türkiye'nin yanı sıra Çin, Vietnam, Meksika, Nepal, Hindistan, Arjantin, Tayvan, Bangladeş gibi ülkelerde yer almaktadır.

Son yıllarda farklı fonksiyonel gruplarla fonksiyonlandırılan kaliksarenlerin katyon ve anyonların katı-sıv1, sıv1-sıvı ekstraksiyon ve membran çalışmalarında kullanılması literatürde fazlasıyla yer edinmektedir [16-18]. Nicolai I. Nikishkin ve ark. bir dizi pirazin sübstitüe kaliksaren sentezlemiş ve bunları Evropiyum (Eu) ve Amerikyum (Am)'a karşı sıv1-sıv1 ektraksiyon özellikleri incelenmiştir. Sentezlenen ligandların, f-blok metal iyonlarına karşı çok yüksek bir afinite ve Am (III) için seçicilik gösterdiği rapor edilmiştir [19]. Bu çalışmada pirazin karbonil sübstitüe kaliks[4]aren türevi sentezlenmiş ve yapısı standart spektroskopik yöntemler (FT-IR, ${ }^{1} \mathrm{H}-\mathrm{NMR}$ ve kütle) ve elementel analiz ile aydınlatılmıştır. Ayrıca sentezlenen yeni kaliksaren türevinin bazı toksik metallere ve oksianyonlarına (kromat ve arsenat) karşı sıvı-sıvı ektraksiyon özellikleri incelenmiştir.

\section{Materyal ve Metot}

\subsection{Kullanılan Kimyasallar}

Sulu fazın pH'ı uygun miktarda $\mathrm{HCl}$ veya $\mathrm{NaOH}(0,1 \mathrm{M})$ karıştırılarak ayarlandı. Diklormetan, 4-tertbutil fenol, kolon kromatografisi için silika jel 60, dikromat $\left(\mathrm{Na}_{2} \mathrm{Cr}_{2} \mathrm{O}_{7}\right)$ ve arsenat $\left(\mathrm{Na}_{2} \mathrm{HAsO}_{4}\right)$ Merck firmasından hazır olarak temin edilmiştir. İnce tabaka kromotografisi (İTK) silikajel tabakasıyla (Merck $60 \mathrm{~F}_{254}, \mathrm{SiO}_{2}$ ) kaplanmış alüminyum plakalar ile yapılmıştır. Kolon kromotografisinde silika jel 60 (Merck, tanecik büyüklügü 0,040-0,063mm, 230-240 mesh) kullanılmıştır. Pirazin-2-karbonil klorit, Alfa Aesar firmasından hazır olarak temin edilmiştir.

\subsection{Kullanılan Cihazlar}

Kromat ve arsenat çözeltileri, Millipore Milli-Q Plus su arıtma sisteminden alınan ultra saf su ile hazırlandı. $\mathrm{pH}$ ayarlaması $\mathrm{pH}$ metre (WTW pH 720) ile yapıldı. UV-Vis spektrumları Shimadzu 2101 UV spektrofotometre ile FTIR Perkin Elmer Spectrum BX FT-IR sistemi, kütle spektrumu bir Bruker Micro ES ${ }^{+}$ile, ${ }^{1} \mathrm{H}$ NMR spektrumları ise TMS kullanılarak bir Varian $500 \mathrm{MHz}$ spektrometrede $\mathrm{CDCl}_{3}$ çözücü içerisinde kaydedilmiştir. H-NMR spektrumunda kimyasal kayma değerleri $(\delta)$ ppm olarak alınmıştır. 


\subsection{Sivı-Sıvı Ekstraksiyon}

Sıv1-sıv1 ektraksiyon, Pedersen prosedürüne göre yapılmıştır [20]. Oksianyon ekstraksiyonu için, $10 \mathrm{~mL}$ ultra saf su içerisinde $1 \times 10^{-4} \mathrm{M}$ dikromat $\left(\mathrm{Na}_{2} \mathrm{Cr}_{2} \mathrm{O}_{7}\right)$ veya arsenat $\left(\mathrm{Na}_{2} \mathrm{HAsO}_{4}\right)$ çözeltisi, $1 \times 10^{-3} \mathrm{M}$ $10 \mathrm{~mL}$ bileşik 3 ile karıştırılarak ağzı kapalı bir erlene alındı. Metal ekstraksiyonu için ise, ultra saf su içerisinde $1 \times 10^{-5} \mathrm{M}$ metal pikrat çözeltisi ile diklormetan içerisindeki $1 \times 10^{-3} \mathrm{M} 10 \mathrm{~mL}$ bileşik 3 ile karıştırılarak ağzı kapalı bir erlen içerisine alındı. Hazırlanan karışımlar mekanik sallayıcıda 3 dakika hızlı bir şekilde sallandı. Daha sonra 1 saat oda sıcaklığında orta devirde sallandı. Sulu ve organik fazın tamamen ayrılması için yarım saat beklendi. Kromat iyon ekstraksiyonu 610nm'de, arsenat ekstraksiyonu 346nm'de ve metal pikrat ekstraksiyonu 354nm'de UV-Vis spektrometresi (Shimadzu 2101) kullanılarak belirlenmiştir.

$$
E \%=\frac{A_{0}-A}{A_{0}} x 100
$$

Burada, $\mathrm{A}_{\circ}$ değeri sulu fazdaki oksianyon $\left(1 \times 10^{-4} \mathrm{M}\right)$ veya metal pikratın $\left(1 \times 10^{-5} \mathrm{M}\right)$ başlangıç absorbansıdır. A değeri ise ektraksiyon olduktan sonra sulu fazın absorbansını göstermektedir. Ekstraksiyon yüzdesi yukarıdaki formül kullanılarak hesaplanmıştır.

\section{Sentez}

Bileşik 1 ve 2 literatüre göre sentezlenmiştir [21, 22].

\section{5,11,17,23-Tetra-ter-bütil-25,27-dipirazinkarbonil-26,28-dimetoksikaliks[4]aren Sentezi(3)}

$2 \mathrm{~g}(3 \mathrm{mmol})$ bileşik $2,122 \mathrm{~g}(8.8 \mathrm{mmol})$ potasyum karbonat ve $0,84 \mathrm{~g}(6 \mathrm{mmol})$ pirazin-2-karbonil klorit azot atmosferi ve bir geri soğutucu altında $200 \mathrm{~mL}$ susuz aseton içerisinde 24 saat karıştırılarak kaynatılır. Çözücü kuruluğa kadar distile edilir. Katı kısım kolon kromotografisi (Silikajel; Aseton/Hekzan (1/4) ile saflaştırılır. Verim: 2,21 g (\%84). IR: 3065 (aromatik C-H), 2921-2850 (alifatik C-H), $1766 \mathrm{~cm}^{-1}(\mathrm{C}=\mathrm{O}) .{ }^{1} \mathrm{H}$ NMR $\left(\mathrm{CDCl}_{3}\right): \delta 0,98$ (s, $\left.18 \mathrm{H}, \mathrm{t}-\mathrm{Bu}\right), 1,21$ (s, $\left.18 \mathrm{H}, \mathrm{t}-\mathrm{Bu}\right), 3,10$ (s, $\left.6 \mathrm{H}, \mathrm{OCH}_{3}\right), 3,23\left(\mathrm{~d}, \mathrm{~J}=11,3 \mathrm{~Hz}, 4 \mathrm{H}, \mathrm{AB}\right.$ sistem, $\left.\mathrm{ArCH}_{2} \mathrm{Ar}\right), 4,43(\mathrm{~d}, \mathrm{~J}=11,3 \mathrm{~Hz}, 4 \mathrm{H}, \mathrm{AB}$ sistem, $\mathrm{ArCH}_{2} \mathrm{Ar}$ ), 6,89 (s, 4H, ArH), 7,12 (s, 4H, ArH), 8,35 (d, J=6.5 Hz, 4H, PyzH), 9,03 (s, 2H, PyzH). Hesaplanan: $\mathrm{C}_{56} \mathrm{H}_{64} \mathrm{O}_{6} \mathrm{~N}_{4}$ : C, 76,65; H, 7,25\%; N, 6,30 \% Bulunan: C, 76,94; H, 8,11\%; N, 6,42. MS (ES+), (m/z): Hesaplanan: $\mathrm{C}_{56} \mathrm{H}_{64} \mathrm{O}_{6} \mathrm{~N}_{4}, 889,13$; Bulunan: 890,68 [M+1] $]^{+}$.

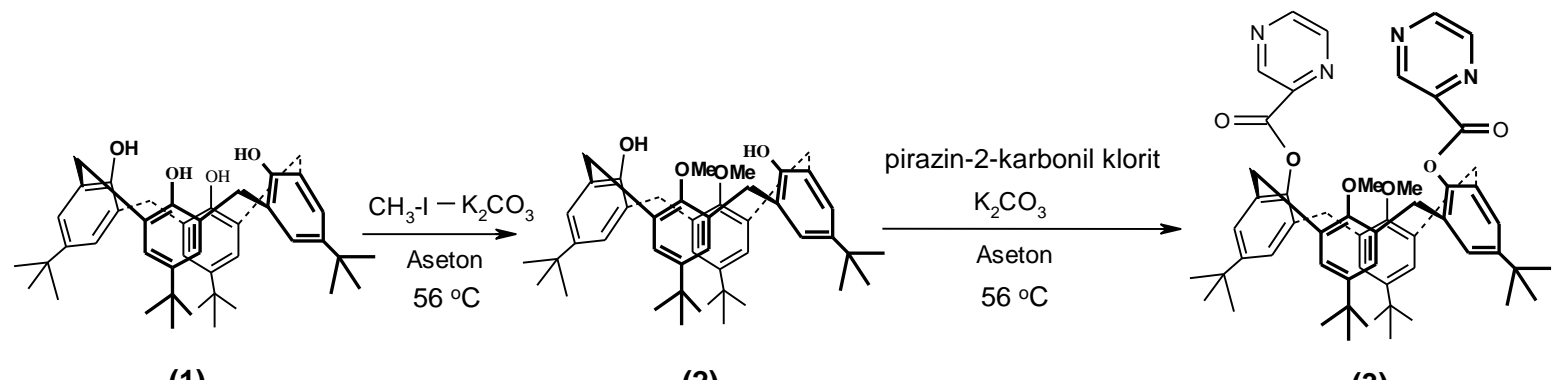

(1)

(2)

(3)

Şekil 1. Kaliks[4]aren pirazin-2-karboksilat türevi

\section{Bulgular ve Tartışma}

Bu çalışmada pirazin substitüe kaliksaren sentezleyerek toksik metal ve oksianyonların (kromat ve arsenat) atık sulardan temizlenmesi amacıyla sıv1-sıvı ekstraksiyon çalışmaları yapılmıştır. Yeni sentezlenen bileşik 3 'ün yapısı, ${ }^{1}$ H NMR spektroskopisi, kütle spektroskopisi, FTIR ve element analizi ile aydınlatılmıştır. Bileşik 3 'in FTIR spektrumunda $3297 \mathrm{~cm}^{-1}$ deki OH titreşim pikinin kaybolduğu ve yerine $\mathrm{C}=\mathrm{O}$ fonksiyonel gruplara ait yeni bir titreşim pikinin $1766 \mathrm{~cm}^{-1}$, de gözlenmesiyle reaksiyonun gerçekleştiği anlaşılmıştır. Ayrıca ${ }^{1} \mathrm{H}-\mathrm{NMR}$ spektrumunda $\mathrm{OH}$ pikine ait olan sinyalin kaybolarak yerine 
pirazin aromatik halkasına ait olan 9,03ppm ve $8,35 \mathrm{ppm}$ 'de sinyaller gelmiştir. Aromatik köprü $\left(\mathrm{ArCH}_{2} \mathrm{Ar}\right.$ ) protonlarına ait olan sinyallerin 3,23 ppm ve 4,43 ppm de AB sistem şeklinde iki çift dublet olarak rezonans olması bileşik 3'ün koni konformasyonuna sahip olduğunun kanıtıdır. Kütle spektrumunda moleküler iyon piki 890,68 $[\mathrm{M}+1]^{+}$'da saptanmıştır.

Koni konformasyonu diğer konformasyonlara göre (1,3 karşılıkl1, 1,2 karşılıklı ve kısmi koni) daha kararlı bir yapıya sahip olduklarından dolayı iyonlar ve metaller ile daha yüksek oranda kompleks yapabilmektedir. Yani kaliksarenlerin koni konformasyonunun uzaysal alanda eğilme ya da bükülmesi sonucunda molekül boşluğunda (kavite) bir değişiklik olmamaktadır. Bundan dolayı bu çalışmada kullanılan bileşik 3 koni konformasyonunda sentezlenmiştir. Kaliksarenlerin konformasyonu aril halkaları arasındaki $\mathrm{CH}_{2}$ protonlarının ${ }^{1} \mathrm{H}-\mathrm{NMR}$ 'deki sinyalleri ile anlaşılmaktadır [23].

Katyonlar ile taşıyıcı reseptörler arasındaki etkileşimler genellikle kovalent olmayan (hidrojen bağı, iyon etkileşimi, $\pi$ - $\pi$ etkileşimi vb.) etkileşimlere dayanmaktadır. Metal ektraksiyonunda ilk olarak pikrik asidin ekstraksiyona etkisini incelemek amacıyla bileşik 3'ün olmadığı ortamda ektraksiyon çalışması yapılmıştır. Yapılan bu kontrol çalışmasında sulu fazdan organik faza herhangi bir metal pikratın geçmediği görülmüştür. Bu çalışma tüm metal pikratlar için ayrı ayrı yapılmıştır. Ayrıca çalışma oksianyonlar içinde yapılmış yine herhangi bir ekstrakt gözlenmemiştir. Sübstitüe edilmemiş kaliks[4]arenlerin metalleri ve anyonları sulu fazdan organik faza taşımadığı bilinmektedir [24, 25]. Bu sonuç organik faza taşınan metal pikratların bileşik $\mathbf{3}$ 'ün pirazin grubu ile yaptığı kompleks sonucunda olduğunu göstermektedir. Ekstraksiyon sonuçlarına göre bileşik 3'ün metal pikratları yüksek oranda sulu fazdan organik faza taşıdığı görülmektedir (Şekil 2). Yüksek ekstraksiyon yüzdesi, pirazin halkasındaki azot atomları ile metaller arasında oluşan dipol-iyon etkileşimden kaynaklandığı düşünülmektedir. Ayrıca +1 değerlikli sodyum ve potasyum diğer +2 değerlikli metallere $(\mathrm{Co}, \mathrm{Ni}, \mathrm{Cu}$, $\mathrm{Cd}, \mathrm{Hg}$ ve $\mathrm{Pb}$ ) göre daha düşük ekstraksiyon yüzdesi sergilemektedirler. $\mathrm{Bu}$ da dipol-iyon etkileşimin ekstraksiyon üzerinde etkili olduğunun kanıtıdır.

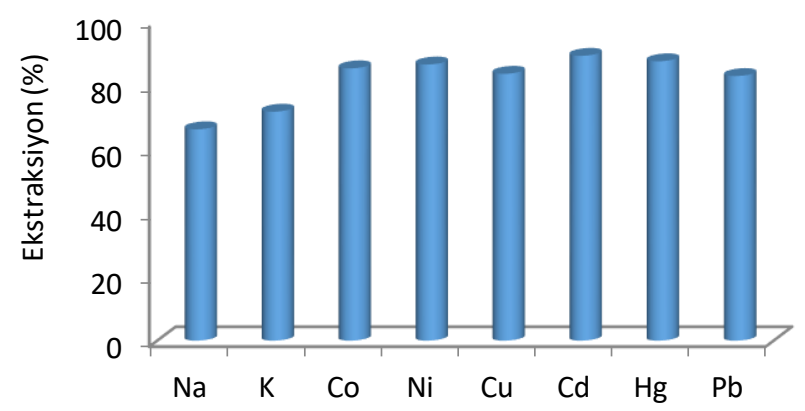

Şekil 2. Metal pikratların Bileşik 3 ile ekstraksiyon yüzdesi

Krom doğal ortamda genellikle $\mathrm{Cr}(\mathrm{III})$ ve $\mathrm{Cr}(\mathrm{VI})$ olarak iki formda bulunmaktadır. $\mathrm{Cr}$ (III)'ün kristal formu doğada krom hidroksit $\left[\mathrm{Cr}(\mathrm{OH})_{3}\right]$ ve krom oksit $\left[\mathrm{Cr}_{2} \mathrm{O}_{3}\right]$ olarak bunmaktadır. Her iki bileşik de suda az miktarda çözünür ve yüksek dozlarda düşük akut ve kronik toksisite sergilemektedirler. Üç değerlikli krom, insanlar için temel bir besin olarak kabul edilirken, Cr (VI) kanserojen olup oksidant ve toksisitesi diğer Cr bileşiklerine göre çok yüksektir. Kromat $\left(\mathrm{CrO}_{4}{ }^{2-}\right)$, bikromat $\left(\mathrm{HCrO}_{4}{ }^{-}\right)$ve dikromat $\left(\mathrm{Cr}_{2} \mathrm{O}_{7}{ }^{2-}\right)$ gibi toksik $\mathrm{Cr}(\mathrm{VI})$ içeren krom anyonları, alkali ve hafif asidik koşullar altında toprakta güçlü bir şekilde tutunmaktadır [26]. Kromun atık sudan ekonomik olarak geri kazanılması, çevresel etkisini en aza indirgemek için çok önemlidir. $\mathrm{Cr}(\mathrm{VI})$ 'nın uzaklaştırılması için iyon değişimi, adsorpsiyon, solvent ekstraksiyon ve sıvı membran gibi çeşitli fizikokimyasal yöntemler üzerinde çalışılmışıır. Sıvı-sıvı ekstraksiyon, metal geri kazanımı da dâhil olmak üzere ayırma ve saflaştırma yöntemi olarak kullanılan en etkili yöntemlerdendir.

Bileşik 3'ün kromat anyonu taşıma özelliğini incelemek amacıyla sıvı-sıvı ekstraksiyon deneyleri yapılmıştır. Kromat ekstraksiyonunda en önemli parametre $\mathrm{pH}$ olduğu için deneyler farklı pH değerlerinde gerçekleştirilmiştir. Ekstraksiyon verilerine göre bileşik 3'ün pH düştükçe dikromat anyonunu yüksek oranlarda organik faza taşıdığı görülmektedir. En yüksek ekstraksiyon yüzdesi $\mathrm{pH}=1,5^{\prime}$ te $\% 91,8$ olarak bulunmuştur. $\mathrm{pH} 6,5^{\prime}$ te ise organik faza taşınım olmamıştır (Şekil 3). $\mathrm{Cr}(\mathrm{VI})$ hafif asidik ve alkali çözeltilerde $\mathrm{CrO}_{4}{ }^{2-}$ formunda iken düşük $\mathrm{pH}$ değerlerinde $\mathrm{HCrO}_{4}{ }^{-}$formunda bulunmaktadır. Ayrıca mono anyon $\left(\mathrm{HCr}_{2} \mathrm{O}_{7}^{-}\right)$dianyonik $\left(\mathrm{Cr}_{2} \mathrm{O}_{7}^{2-}\right)$ formdan daha az hidrasyon serbest 
enerjisine sahiptir. Dolayısıyla mono anyon formunun organik faza taşınması dianyonik forma göre çok daha kolaydır. Ayrıca, bileşik 3'de bulunan pirazin grubundaki azotlar ile anyon arasında güçlü elektrostatik etkileşim ve kovalent bağ oluşmaktadır. Pirazindeki azotların protonlanmasıyla bu etkileşimler daha da güçlenmektedir.

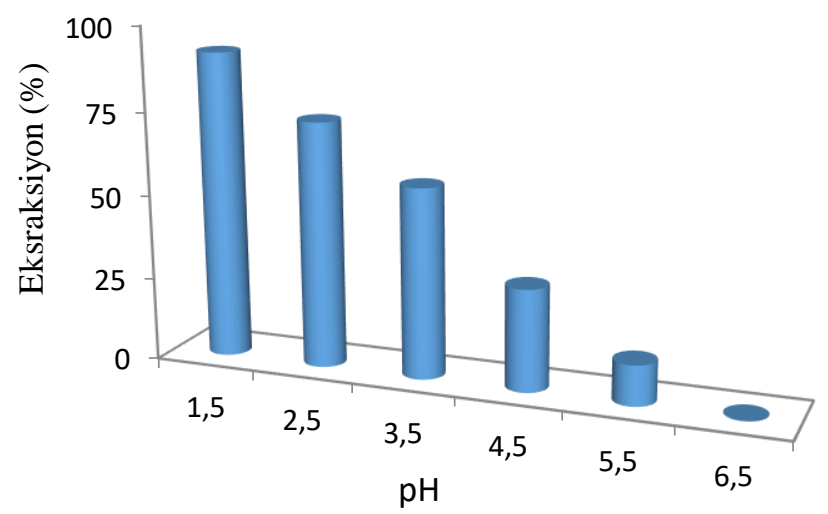

Şekil 3. Dikromat anyonunun Bileşik 3 ile farklı pH'lardaki ekstraksiyon yüzdesi

Arsenik türleri, bazik pH değerlerinde $(\mathrm{pH} 8-11)$ dianyon $\left(\mathrm{HAsO}_{4}{ }^{2-}\right)$, ortalama asidik koşullar (pH 3-6) monoanion $\left(\mathrm{H}_{2} \mathrm{AsO}_{4}^{-}\right)$ve asidik koşullar ( $\mathrm{pH}$ 1-3) $\mathrm{H}_{3} \mathrm{AsO}_{4}$ formları halinde bulunmaktadır [27].

$$
\begin{array}{ll}
\mathrm{H}_{3} \mathrm{AsO}_{4} \leftrightarrows \mathrm{H}_{2} \mathrm{AsO}_{4}{ }^{-}+\mathrm{H}^{+}, & \mathrm{pKa} 1=2,3 \\
\mathrm{H}_{2} \mathrm{AsO}_{4}{ }^{-} \leftrightarrows \mathrm{HAsO}_{4}{ }^{2-}+\mathrm{H}^{+}, & \mathrm{pKa} 2=6,8 \\
\mathrm{HAsO}_{4}{ }^{2-} \leftrightarrows \mathrm{AsO}_{4}{ }^{3-}+\mathrm{H}^{+}, & \mathrm{pKa} 3=11,6
\end{array}
$$

Ayrıca, dianiyonik form $\mathrm{HAsO}_{4}{ }^{2-}$ monoanion $\left(\mathrm{H}_{2} \mathrm{AsO}_{4}{ }^{-}\right)$ile karşılaştırıldığında, daha küçük bir serbest hidrasyon enerjisine sahiptir [28]. Arsenat iyonlarının çevresindeki oksit kısımlarıyla konakçı molekülle (bu çalışmada kaliksaren) hidrojen bağları ile kompleks oluşturabilmektedirler. $\mathrm{Bu}$ amaçla, arsenat iyonlarının sıvı-sıvı ekstraksiyon çalışmaları $\mathrm{pH}$ 1,5-7,0 aralığında, bileşik 3 kullanılarak gerçekleştirilmiştir. Ekstraksiyon sonuçları Şekil 4'de gösterilmektedir. Ekstraksiyon sonuçları incelendiğinde en iyi $\mathrm{pH}$ değerinin 3,5 olduğu görülmektedir. Arsenat $\mathrm{pH}$ 1,5'de $\mathrm{H}_{3} \mathrm{AsO}_{4}$ formundadır. $\mathrm{Bu}$ formda bileşik $\mathbf{3}$ ile arasındaki elektrostatik etkileşim azaldığından dolayı ektraksiyon yüzdesi $\mathrm{pH}$ 3,5'e göre daha düşük olmaktadır.

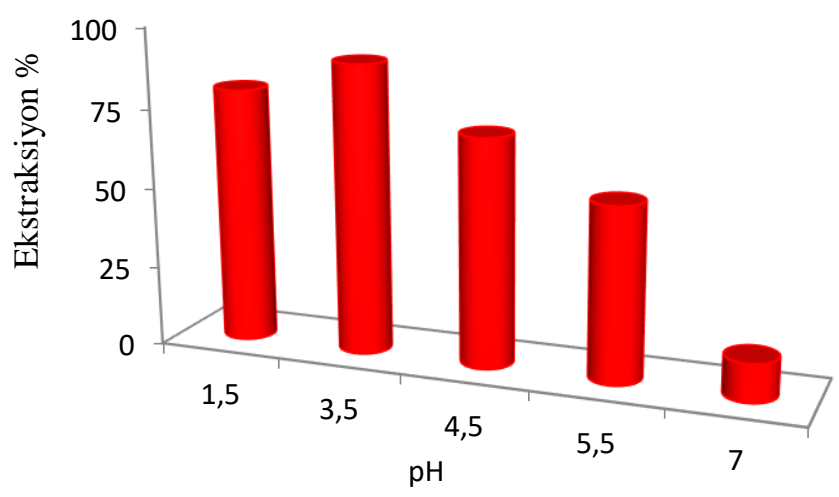

Şekil 4. Arsenat anyonunun Bileşik 3 ile farklı pH'lardaki ekstraksiyon yüzdesi

Bileşik 3 ile dikromat ve arsenat anyonu arasındaki stokiyometrisini bulmak için Job's Plot analiz yöntemi kullanılmıştır. Kompleksin stokiyometrik oranı, oluşan kompleksin UV-Vis spektrumunun serbest ligandların spektrumları ile karşılaştırılarak tespit edilebilir. Ligand-iyon karışımında bir absorpsiyon bandının şiddetinin artması veya yeni bir absorpsiyon bandının meydana gelmesi kompleks oluşumun kanıtıdır. $1 \times 10^{-3} \mathrm{M}$ kaliksarenin UV-Vis spektrumu alındıktan sonra 
farklı oranlarda $\left(9: 1\right.$ - 1:9) dikromat $\left(\mathrm{Na}_{2} \mathrm{Cr}_{2} \mathrm{O}_{7}\right)$ veya arsenat $\left(\mathrm{Na}_{2} \mathrm{HAsO}_{4}\right)$ çözeltisi $\left(1 \times 10^{-3} \mathrm{M}\right)$ ile karıştırılarak UV-Vis spektrumu alındı. Bileşik 3 ile oksianyonlar arasındaki elektrostatik etkileşim bileşik 3'ün 223nm'deki bandının şiddetini artırmaktadır. Bu da kompleks oluşumunun kanıtıdır. Bu bandın (223 nm) absorpsiyon şiddeti grafiğ geçirildiğinde mol franksiyon oranı 0,5 olarak bulunmuştur (Şekil 5). Bu değer 1:1 kompleks oluştuğunu göstermektedir. Bileşik 3 ile dikromat $(\mathrm{pH}=1,5)$ ve arsenat $(\mathrm{pH}=3,5)$ anyonları arasında önerilen kompleksleşme modeli Şekil 6'da gösterilmektedir.

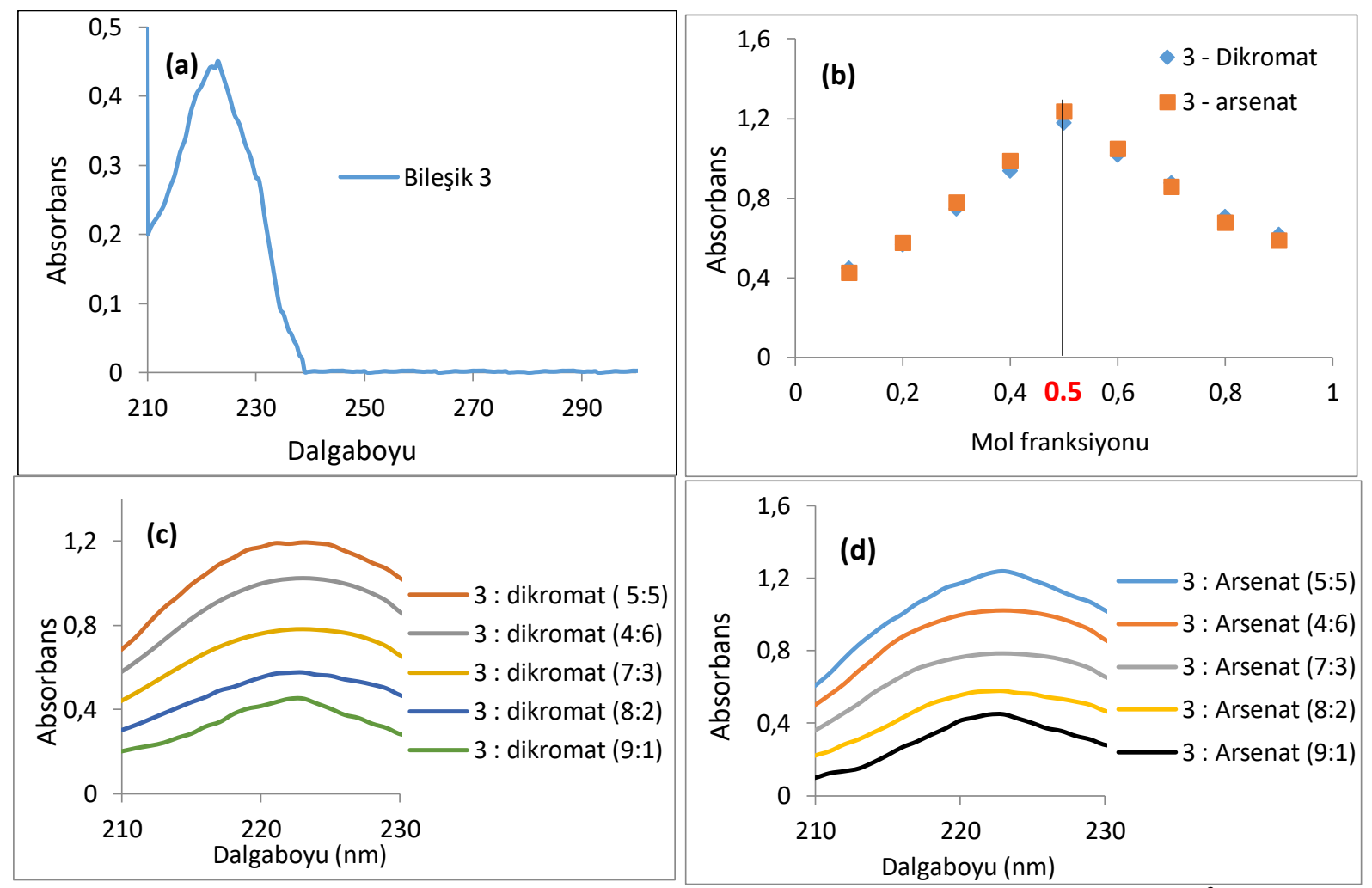

Şekil 5. Job's Plot analizi (a) Bileşik 3'ün diklormetan içerisinde UV-Vis spektrumu, $1 \times 10^{-3} \mathrm{M}$. (b) mol franksiyonu, (c) Bileşik 3 ile Dikromat'ın farklı oranlardaki karışımlarının UV-Vis spektrumları (d) Bileşik 3 ile Arsenat'ın farklı oranlardaki karışımlarının UV-Vis spektrumları

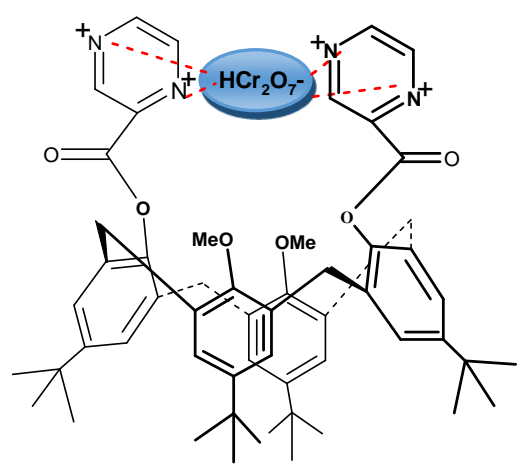

$\mathrm{pH}=1.5$

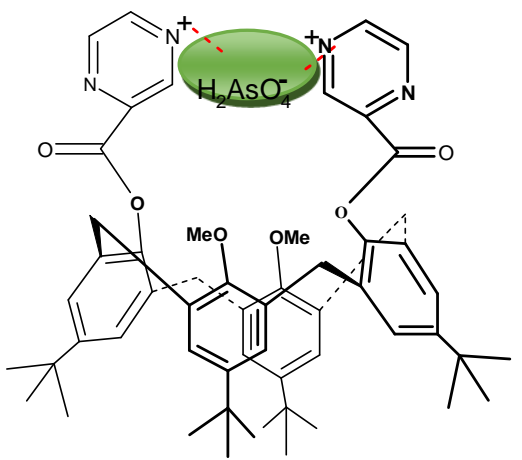

$\mathrm{pH}=3.5$

Şekil 6. Bileşik 3 ile oksianyonlar (Dikromat ve Arsenat) arasında önerilen kompleks modeli. 


\section{Sonuç ve Öneriler}

$\mathrm{Bu}$ çalışmada 5,11,17,23-Tetra-ter-bütil-25,27-dipirazinkarbonil-26,28-dimetoksikaliks[4]aren (3) sentezlenmiş ve yapısı standart spektroskopik yöntemler $\left({ }^{1} \mathrm{H}-\mathrm{NMR}\right.$, kütle ve FT-IR) ve elementel analiz ile tamamen karakterize edilmiştir. Sentezlenen yeni kaliksaren türevi (3), ciddi çevresel ve sağlik problemlerine yol açan toksik metaller ile oksianyonların (kromat ve arsenat) atık sulardan temizlemek amacıyla sıvı-sıvı ekstraksiyon çalışmaları yapılmıştır. Ekstraksiyon çalışmaları sonucunda bileşik 3 'ün pH 1,5'da kromat anyonunu yüksek oranda sulu fazdan organik faza taşıdığı görülmüsşür. Ayrıca bileşik 3, arsenat anyonunu $\mathrm{pH} 3,5$ 'da en yüksek oranda sulu fazdan organik faza taşıdığı görülmüştür. Sonuç olarak bu bileşiğin (3) toksik metaller ile toksik ve kanserojen olan dikromat ve arsenat anyonlarının temizlenmesinde kullanılabileceği görülmektedir.

\section{Kaynaklar}

[1] Gutsche CD. 1998. Calixarenes Revisited. The Royal Society of Chemistry, Cambridge.

[2] Vicens J., Bohmer V. 1991. Calixarenes: A versatile Class of Macrocyclic Compounds. Topics in Inclusion Science, Kluwer Academic Publishers, Dordrecht.

[3] Yilmaz M., Sayin S. 2016. Calixarenes and Beyond. 1. Bask1, Seattle, USA, 27 (719-742).

[4] Roundhill M.D. 1995. Metal Complexes of Calixarenes. Book Editor: Kenneth D. Karlin. Progress in Inorganic Chemistry, Volume 43. Online ISBN: 9780470166444.

[5] Rajamani T., Ramasami S., Langerwerf J.S.A., Schappman J.E. 1995. Environment management in tanneries feasible chromium recovery and reuse system. Proceedings of 3rd International Conference on Appropriate Waste Management Technologies for Developing Countries, Nagpur, 965-973.

[6] Srinath T., Verma T., Ramteke P.W., Garg S.K. 2002. Chromium (VI) biosorption and bioaccumulation by chromate resistant bacteria. Chemosphere, 48 (4): 427-435.

[7] Habuda-Stanic M., Kalajdzic B., Kules M., Velic N. Stanic. 2008. Arsenite and Arsenate Sorption by Hydrous ' Ferric Oxide/Polymeric Material, Desalination, 229 (1): 1-9.

[8] Yolcubal I., Akyol N.H. 2008. Adsorption and transport of arsenate in carbonate-rich soils: coupled effects of nonlinear and rate-limited sorption. Chemosphere, 73 (8): 1300-1307.

[9] Hering J.G., Chen P.Y., Wilkie J.A., Elimelech M. 1997. Arsenic removal from drinking water during coagulation. J. Environ. Eng., 123 (8): 800-807.

[10] Viraraghavan T., Subramanian K.S., Aruldoss J.A. 1999. Arsenic in drinking waterproblems and solutions. Water Sci. Technol., 40 (2): 69-76.

[11] IPCS. 2001. Environmental Health Criteria 224, Arsenic and Arsenic Compounds, 2nd ed., World Health Organization, Geneva, Switzerland.

[12] Hall A.H. 2002. Chronic Arsenic Poisoning. Toxicol. Lett., 128 (1): 69-72.

[13] Valenzuela O., Germolec D., Borja-Aburto V., Contreras-Ruiz J., Garcia-Vargas G., Delrazo L. 2007. Chronic arsenic exposure increases TGFalpha concentration in bladder urothelial cells of Mexican populations environmentally exposed to inorganic arsenic. Toxicol. Appl. Pharmacol., 222 (3): 264-70.

[14] Bayrakci M., Ertul S., Yilmaz M. 2009. Synthesis of Di-Substituted Calix[4]arene-based Receptors for Extraction of Chromate and Arsenate Anions. Tetrahedron, 65 (38): 7963-7968.

[15] World Health Organization (WHO) 2001. Arsenic in Drinking Water (Geneva: United Nations, 2001).

[16] Roundhill D.M., Solangi I. B., Memon S., Bhanger M. I., Yilmaz M. 2009. The Liquid-Liquid Extraction of Toxic Metals (Cd, $\mathrm{Hg}$ and $\mathrm{Pb}$ ) by Calixarenes. Pak. J. Anal. Environ. Chem., 10 (1): 1-13.

[17] Kamboh M.A., Memon S., Zardarı L.A., Nodeh H.R., Sherazı S.T.H, Y1lmaz M. 2018. Removal of toxic metals from canola oil by newly synthesized calixarene-based resin. Turkish Journal of Chemistry, 42: $918-928$.

[18] Sliwa W., Girek T. 2010. Calixarene complexes with metal ions. Journal of Inclusion Phenomena and Macrocyclic Chemistry, 66 (1-2): 15-41. 
[19] Nikishkin N.I., Huskens J., Ansari S.A., Mohapatra P.K., Verboom W. 2013. Pyrazinefunctionalized calix[4]arenes: synthesis by palladium-catalyzed cross-coupling with phosphorus pronucleophiles and metal ion extraction properties. New J. Chem., 37: 391-402.

[20] Pedersen C.J. 1967. Cyclic Polyethers and Their Complexes with Metal Salts. J. American Chem. Society, 89: 7017-7036.

[21] Gutsche C.D., Lin L.-G. 1986. Calixarenes 12: The synthesis of functionalized calixarenes. Tetrahedron, 42 (6): 1633-1640.

[22] Elizabet M., Collins M., McKeevey A., Madigan E., Moran M.B., Owens M., Ferguson G., Harris S.J. 1991. Chemically Modified Calix[4]arenes, Regioselective Synthesis of 1,3-(Distal) Derivatives and Related Compounds. X-Ray Crystal Structure of Diphenol-Dinitrile. Chem. Soc. Perkin. Trans., 12: 3137-3142.

[23] Wamoto K., Ikeda A., Araki K., Seiji Shinkai T.H. 1993. Cone"-"Partial-cone” Isomerism in Tetramethoxycalix[4]arenes. Influence of solvent polarity and metal ions. Tetrahedron, 49 (44): 9937-9946.

[24] Gungor O., Memon S., Y1lmaz M., Roundhill D.M. 2005. Synthesis of alkyl nitrile and alkyl benzonitrile derivatives of calix [4] arene and their polymer supported analogues: a comparative study in two-phase extraction systems. Reactive and Functional Polymers, 63 (1): 1-9.

[25] Gubbuk I.H., Gungor O., Alpoguz H.K., Ersoz M., Y1lmaz M. 2010. Kinetic study of mercury (II) transport through a liquid membrane containing calix [4] arene nitrile derivatives as a carrier in chloroform. Desalination, 261 (2): 157-161.

[26] Bozkurt S., Karakucuk A., Sirit A., Yilmaz M. 2005. Synthesis of two calix[4]arene diamide derivatives for extraction of chromium(VI). Tetrahedron, 44 (61): 10443-10448.

[27] Yusof A.M., Malek N.A.N.N. 2009. Removal of $\mathrm{Cr}(\mathrm{VI})$ and $\mathrm{As}(\mathrm{V})$ from aqueous solutions by HDTMA-modified zeolite Y. Journal of Hazardous Materials, 162 (2): 1019-1024.

[28] Qureshi I., Memon S. 2012. Synthesis and Application of Calixarene-based Functional Material for Arsenic Removal from Water. Applied Water Science, 2 (3): 177-86. 